\title{
КОНЦЕПЦИЯ ЧЕЛОВЕЧЕСКОГО КАПИТАЛА В РАЗВИТИИ КОНКУРЕНТОСПОСОБНОСТИ МЕДИЦИНСКИХ УСЛУГ
}

\author{
(C) 2019 Герасимова Светлана Витальевна \\ кандидат экономических наук, доцент \\ Московский государственный медико-стоматологический университет им. А.И. Евдокимова, \\ Россия, Москва \\ E-mail: lanapost@inbox.ru
}

В статье рассмотрена проблема развития конкурентоспособности медицинских услуг на основе концепции человеческого капитала. Приведена система агрегированных моделей оценки качества и конкурентоспособности медицинских услуг, основанная на концепции развития человеческого капитала и категории нормы потребительной стоимости.

Ключевые слова: конкурентоспособность, медицинская услуга, агрегированная модель, развитие, человеческий капитал, качество, норма потребительной стоимости медицинских услуг, норма потребительной стоимости человеческого капитала.

В статье рассмотрен агрегированный подход к анализу развития конкурентоспособности медицинских услуг на основе концепции человеческого капитала. Ключевыми характеристиками развития человеческого капитала приняты норма потребительной стоимости медицинских услуг и норма потребительной стоимости человеческого капитала. В качестве модели конкурентоспособности медицинских услуг принята параметрическая модель. Рассмотрена оптимизация инвестирования в согласованное развитие содержания медицинской услуги и развитие человеческого капитала. Приведены иллюстративные примеры, демонстрирующие эффективность предложенных агрегированных моделей.

Развитие конкурентоспособности медицинских услуг является актуальной социально-экономической задачей и заключается в разработке и оптимизации целевой программы опережающего инвестиционно-инновационного развития качества услуг и факторов их производства при минимальных издержках и высокой оперативности предоставления. Ускоренное развитие научно-технического прогресса в медицине, обусловленное созданием специализированных информационно-коммуникационных систем искусственного интеллекта, открыли новые возможности количественного и качественного улучшения состояния здоровья трудовых ресурсов и продолжительности трудоспособного возраста в сфере квалифицированного труда как основы экономической эффективности человеческого капитала, - ключевого фактора эконо- мического роста национальной экономики.

Главной особенностью медицинских услуг является их неотделимость от субъекта предоставления - врача. Это означает, что в состав потребительских характеристик медицинской услуги входят не только ее ценовые и неценовые свойства, но и потребительские характеристики врача (ПХВ), имеющие для пациента существенное значение. К таким характеристикам, на наш взгляд, относятся: возраст, профессиональная компетентность, опыт работы, интеллект, коммуникативность, результативность, личная ответственность, оперативность, этичность и др. Перечисленный состав потребительских характеристик субъекта оказания медицинской услуги позволяет сформировать модель «идеального врача» как совокупность наиболее предпочтительных значений этих характеристик при выбранной шкале их измерения.

Например, в лингвистической трехразрядной шкале: «низкий» (Н), «средний» (C), «высокий» (В), - желаемые потребителями класса «стандарт» уровни потребительских характеристик врача и их относительная важность для потребителей приведены в табл. 1. Для потребителей медицинских услуг эконом-класса и элит-класса желаемые значения потребительских характеристик субъекта услуг принимают другие значения, изменяется их относительная важность. Соответственно, для неоднородного, многосегментного рынка необходимо иметь как минимум три модели «идеального врача».

Применение системного подхода предпо- 
Таблица 1. Пример качественной модели «идеального врача» для потребителей класса «стандарт»

\begin{tabular}{|c|l|c|c|}
\hline № & Потребительская характеристика врача & Относительная важность & Желаемый уровень \\
\hline 1 & Возраст & С & С \\
\hline 2 & Профессиональная компетентность & В & В \\
\hline 3 & Опыт работы & В \\
\hline 4 & Интеллект & В & В \\
\hline 5 & Коммуникативность & С & С \\
\hline 6 & Результативность & В & В \\
\hline 7 & Личная ответственность & В & В \\
\hline 8 & Оперативность & С & С \\
\hline 9 & Этичность & С & C \\
\hline
\end{tabular}

лагает включать в модель «идеального врача» только характеристики с высокой значимостью для потребителей. В этом случае часть характеристик $(1,5,8,9)$ можно не учитывать. Итоговая система показателей, с новой нумерацией, приведена в табл. 2.

Для параметрической оценки конкурентоспособности медицинских услуг целесообразно, на наш взгляд, применить агрегированный подход, в котором итоговая оценка качества услуги представляет собой линейную комбинацию уровней качества ценовых и неценовых характеристик, а также качество человеческого капитала, используемого при предоставлении медицинской услуги. Каждая из характеристик может быть оценена показателем нормы потребительной стоимости (НПС) как средней степени соответствия свойств услуги требовани- ям потребителей. Обозначим НПНц - средняя оценка качества ценовых характеристик услуги; НПСн - средняя оценка качества ее неценовых характеристик, а НПСч - средняя оценка качества человеческого капитала, используемого при оказании медицинской услуги. Тогда формула агрегированной оценки качества услуги НПС получит вид (1):

$$
\begin{aligned}
& \text { НПС = a } \cdot \text { НПСц + в } \cdot \text { НПСн }+ \text { c } \cdot \text { НПСч } \\
& \text { где a, в, с - весовые коэффициенты, } \\
& \mathrm{a}+\mathrm{s}+\mathrm{c}=1
\end{aligned}
$$

Рассмотрим иллюстративный пример, демонстрирующий целесообразность учета качества человеческого капитала при оценке конкурентоспособности медицинских услуг. В табл. 3 приведены оценки характеристик одной и той

Таблица 2. Пример системной информационной модели «идеального врача» для потребителей класса «стандарт»

\begin{tabular}{|c|l|c|}
\hline № & \multicolumn{1}{|c|}{ Потребительская характеристика врача } & Желаемый уровень \\
\hline 1 & Профессиональная компетентность & В \\
\hline 2 & Опыт работы & $\mathrm{B}$ \\
\hline 3 & Интеллект & $\mathrm{B}$ \\
\hline 4 & Результативность & $\mathrm{B}$ \\
\hline 5 & Личная ответственность & . \\
\hline
\end{tabular}

Таблица 3. Пример оценки качества человеческого капитала для одинаковой медицинской услуги двух конкурентных клиник

\begin{tabular}{|c|l|c|c|c|}
\hline № & Потребительская характеристика врача & K-1 & К-2 & Желаемый уровень \\
\hline 1 & Профессиональная компетентность & $\mathrm{C}$ & $\mathrm{B}$ & $\mathrm{B}$ \\
\hline 2 & Опыт работы & $\mathrm{B}$ & $\mathrm{B}$ & $\mathrm{B}$ \\
\hline 3 & Интеллект & $\mathrm{B}$ & $\mathrm{B}$ & $\mathrm{B}$ \\
\hline 4 & Результативность & $\mathrm{B}$ & $\mathrm{C}$ & $\mathrm{B}$ \\
\hline 5 & Личная ответственность & $\mathrm{C}$ & $\mathrm{B}$ & 1 \\
\hline 6 & НПСч & 0,6 & 0,8 & \\
\hline
\end{tabular}


же услуги двух конкурентных медицинских организаций К-1 и К-2.

Пусть значения коэффициентов относительной важности НПСч, НПСн, НПСч таковы:

$\mathrm{a}=0,2 ; \mathrm{B}=0,3 ; \mathrm{c}=0,5$

В табл. 4 приведены исходные значения характеристик качества медицинской услуги двух клиник.

В качестве показателя конкурентоспособности медицинских услуг первой клиники относительно тех же услуг второй клиники примем отношение полученных значений их НПС, приведенных в табл. 4 (2):

$$
\mathrm{k}=\text { НПС } 1 / \text { HПС } 2=0,63 / 0,72=0,875
$$

Для окончательного вывода об уровне конкурентоспособности услуг, следует выбрать функцию качества, устанавливающую взаимосвязь между количественной оценкой конкурентоспособности услуг и лингвистической. В табл. 5 приведен пример решетчатой функции качества.

В соответствии с табл. 5, следует сделать вывод о неконкурентоспособности услуги первой клиники по сравнению со второй. Это означает, что первой клинике следует предпринимать срочные действия по развитию конкурентоспособности услуги.
Рассмотрим решение задачи без учета качества человеческого капитала (табл. 6). В этом случае формула (1) получит более простой вид (3):

$$
\left\{\begin{array}{l}
\text { НПС }=a \cdot \text { НПСц }+ \text { в } \cdot \text { НПС } \\
a+\text { s }=1
\end{array}\right.
$$

В соответствии с рассмотренным примером: $\mathrm{a}=0,4 ; \mathrm{B}=0,6$

Проведем оценку конкурентоспособности услуги первой клиники:

\section{$\mathrm{k}=$ НПС 1 / НПС $2=0,66 / 0,64=1,03$}

Полученный результат позволяет сделать вывод, что услуга первой клиники не уступает в конкурентоспособности второй клинике, то есть потребители воспринимают эти услуги как эквивалентные.

Таким образом, рассмотренные примеры показали, что качество человеческого капитала может быть определяющим фактором конкурентоспособности медицинских услуг. В этом случае становится актуальной задача развития человеческого капитала как альтернатива развитию ценовых и неценовых свойств медицинской услуги. Если предположить, что конкурирующие клиники в равной степени используют результаты научно-технического прогресса в медицине, то становится очевидно, что наиболее предпочтительной альтернативой обеспе-

Таблица 4. Пример агрегированной оценки качества медицинской услуги двух конкурентных клиник

\begin{tabular}{|c|l|c|c|}
\hline № & \multicolumn{1}{|c|}{ НПС } & K-1 & K-2 \\
\hline 1 & НПСц & 0,9 & 0,7 \\
\hline 2 & НПСн & 0,5 & 0,6 \\
\hline 3 & НПСч & 0,6 & 0,8 \\
\hline 4 & НПС & 0,63 & 0,72 \\
\hline
\end{tabular}

Таблица 5. Функция качества для оценки конкурентоспособности услуг

\begin{tabular}{|l|c|}
\hline \multicolumn{1}{|c|}{ Уровень конкурентоспособности услуги } & $\mathrm{k}$ \\
\hline Услуга конкурентоспособна & $>1,1$ \\
\hline Услуга не имеет конкурентных преимуществ & $\sim 1$ \\
\hline Услуга неконкурентоспособна & $<0,9$ \\
\hline
\end{tabular}

Таблица 6. Пример агрегированной оценки качества медицинской услуги двух конкурентных клиник

\begin{tabular}{|c|l|c|c|}
\hline № & \multicolumn{1}{|c|}{ НПС } & К-1 & K-2 \\
\hline 1 & НПСц & 0,9 & 0,7 \\
\hline 2 & НПСн & 0,5 & 0,6 \\
\hline 3 & НПС & 0,66 & 0,64 \\
\hline
\end{tabular}


Таблица 7. Пример матрицы конкурентоспособности

\begin{tabular}{|c|c|c|}
\hline & Py & Рч \\
\hline Су & 1,8 & 0,6 \\
\hline Сч & 1,0 & 1,4 \\
\hline
\end{tabular}

чения конкурентоспособности услуг становится развитие человеческого капитала клиники в наиболее значимом для потребителей направлении. Если конкурирующие клиники имеют различный технический уровень оказания услуг, то возможны две стратегии развития конкурентоспособности услуг: развитие содержания услуг и развитие человеческого капитала. В условиях перспективной неопределенности рынка медицинских услуг, наиболее предпочтительной является смешанная стратегия, то есть инвестирование в развитие собственно услуг и человеческого капитала.

Рассмотрим иллюстративный пример. Обозначим Су - стратегия развития услуг, а Сч - стратегия развития человеческого капитала. Устранение перспективной рыночной неопределенности проведем путем предположения о двух перспективных ситуациях на рынке: Ру увеличение требований рынка к содержанию ус- луги; Рч - увеличение требований рынка к человеческому капиталу. В этом случае моделью перспективной ситуации на рынке медицинских услуг будет матрица конкурентоспособности. Ее конкретный пример приведен в табл. 7:

При применении графического метода анализа задачи определения оптимальной пропорции инвестирования в развитии содержания услуги и человеческого капитала с целью максимизации гарантированного среднего уровня ее конкурентоспособности, получен следующий результат, 70\% запланированной суммы инвестиций следует расходовать на развитие человеческого капитала, а 30\% - на развитие содержания услуги. В этом случае максимальный средний гарантированный уровень конкурентоспособности медицинской услуги примерно составит величину $\mathrm{k}=1,2$, то есть услуга будет конкурентоспособна.

\section{Библиографический список}

1. Герасимова С.В. Качественное прогнозирование микротенденций развития и конкурентных стратегий на рынке услуг. Экономические науки № 12(145), 2016. С. 19-22.

2. Гуськова М.Ф., Стерликов П.Ф., Стерликов Ф.Ф. Экономическая жизнь людей // Экономические науки № 2 (147), 2017. С. 11-15.

3. Гуськова М.Ф., Стерликов П.Ф., Стерликов Ф.Ф. К вопросу оценки бизнеса // Экономические науки № 9(142), 2016, С. 30-36.

4. Проект развития человеческого капитала. Всемирный банк МБPP. URL: https: //www.vsemirnyjbank.org/ru/ publication/human-capital (дата обращения 08.09.2019). 